\title{
Effect of Reye's Syndrome Serum on Isolated Chinchilla Liver Mitochondria
}

James H. Tonsgard and Godfrey S. Getz

Department of Pediatrics and Neurology, Department of Pathology and Biochemistry, and the Joseph Kennedy Mental Retardation Center, University of Chicago Pritzker School of Medicine, Chicago, Illinois 60637

\begin{abstract}
A general impairment of liver mitochondrial enzymes is central to Reye's syndrome (RS). The respiration of isolated liver mitochondria was measured after the addition of concentrated normal serum or RS serum derived from 12 patients. RS serum stimulates oxygen consumption in isolated rat liver mitochondria. This effect is due to $(a)$ the oxidation of uric acid by peroxisomes contaminating the preparation and $(b)$ a stimulation of mitochondrial respiration $\left(1.05 \pm 0.14 \mathrm{nmol}\right.$ of $\mathrm{O}_{2} / \mathrm{min} \cdot \mathrm{mg}$ of protein; control $0.30 \pm 0.08 \mathrm{nmol} \mathrm{O}_{2} / \mathrm{min} \cdot \mathrm{mg}$ ). The stimulation of respiration occurs in the presence of all respiratory substrates, is dependent on the amount of serum added, and represents an uncoupling of oxidative phosphorylation. RS serum reduces ATP formation by 15-76\%. The uncoupling effect correlates with the amount of free fatty acid in the serum sample and resembles the effect induced by the addition of a dicarboxylic fatty acid. Dicarboxylic fatty acids, especially long-chain dicarboxylic acids, impair ATP formation. Dicarboxylic acids were found in the serum of all RS patients and comprised as much as $54 \%$ of the total serum free fatty acids. $90 \%$ of the serum dicarboxylic acids were of 16-18 carbon lengths. The amount of dicarboxylic acids in the RS serum corresponded directly with the reduction in ATP formation by the RS serum. This demonstrates that dicarboxylic acids occur in RS and may be important in the general impairment of mitochondrial function in RS and other disorders where they are present.
\end{abstract}

\section{Introduction}

Reye's syndrome (RS) ${ }^{1}$ is an acute illness of childhood associated with encephalopathy and fatty infiltration of the viscera. The illness follows a viral prodrome in children who are otherwise normal. The change in mental state is accompanied by transient selective liver dysfunction (1). Characteristically the plasma contains elevated levels of glutamic-pyruvic transaminase, glutamic-oxaloacetic transaminase, lactic dehydrogenase and ammonia, and depressed levels of clotting factors with normal or minimally elevated bilirubin. Hypoglycemia is frequently present. Striking elevations in lactate and pyruvate

Address reprint requests to Dr. Tonsgard, Department of Pediatrics, Box 228, University of Chicago, 5841 S. Maryland Avenue, Chicago, IL 60637.

Received for publication 10 September 1984 and in revised form 28 March 1985.

1. Abbreviations used in this paper: BSA, bis silyl acetamide; DNP, dinitrophenol; N, control; RS, Reye's syndrome.

\section{J. Clin. Invest.}

(c) The American Society for Clinical Investigation, Inc.

0021-9738/85/08/0816/10 \$1.00

Volume 76, August 1985, 816-825 are seen as well as elevations in amino acids, specifically alanine and glutamine. Fatty acid metabolism also seems to be impaired with panhypolipidemia, but free fatty acids are elevated over normal levels. Serum VLDL concentration is low (2) and the glucagon/insulin ratio, although elevated, is lower than in diabetic ketoacidosis (3).

The pathologic findings are a striking visceral fatty accumulation and cerebral edema without inflammation (4). It has been suggested that a transient generalized dysfunction of mitochondria after a viral infection may be central to the pathophysiology of this illness (5). This has been most clearly demonstrated in the liver where ultrastructural changes of mitochondria have been described in liver biopsy samples (6), and the assessment of activity of mitochondrial versus cytosol enzymes in liver correlates with these ultrastructural findings: mitochondrial enzymes are depressed whereas cytosol enzymes are normal (7).

Investigations have focused on several hypotheses for the etiology of the mitochondrial disturbance. An underlying inborn metabolic defect, abnormal immune response, exogenous toxin, and an endogenously produced toxin as the result of a viral infection have all been proposed (8). There is relatively little evidence to substantiate an inherent metabolic defect in patients with RS. Circulating immune complexes are present in patients with $\mathrm{RS}(9,10)$. The role of exogenous toxins such as aspirin, insecticide, or aflatoxin is unclear. We have focused on the possibility that a factor present in the serum of patients with RS might affect hepatic mitochondria. Aprille and her co-worker $(11,12)$ reported that concentrates of serum from patients with RS added to isolated rat liver mitochondria stimulated respiration, uncoupled oxidative phosphorylation, and caused structural alteration in rat liver mitochondria. Subsequently, the incremental consumption of oxygen was attributed to the metabolism of uric acid in microbodies that contaminated the rat liver mitochondrial preparations (13). We have come to somewhat different conclusions. We have shown that RS serum does uncouple oxidative phosphorylation and impair ATP formation, and that the characteristics of the factor responsible resemble those of dicarboxylic fatty acids. Dicarboxylic acids were measured and comprise as much as $54 \%$ of the total free fatty acids in RS serum; the amount of dicarboxylic acids present in the serum correlates with the stimulation of respiration and the degree of impairment of ATP formation. Dicarboxylic acids have not previously been appreciated to have toxic effects on mitochondrial function and could play a role in RS.

\section{Methods}

Serum samples were obtained from 12 patients with RS (10 patients in profound coma prior to exchange transfusion and two with delirium that did not progress to coma). Patients ranged in age from 1 to 13 yr. Control $(\mathrm{N})$ serum was used for four healthy young adults or adolescents and from three children in acute diabetic ketoacidosis and 
four children with acute liver disease with encephalopathy. All four patients with liver disease had fatty changes of the liver and two were initially treated as though they had RS. The hospital record of the patients was reviewed for use of aspirin or other medications. Salicylate levels were negative in 9 of the 12 RS patients. In only one case was the level near therapeutic $(12.5 \mathrm{mg} / \mathrm{dl})$. The method used to determine salicylates is sensitive for salicylate metabolites as well (14). The patients were treated with hypertonic glucose and the osmotic diuretic mannitol. Phenobarbital, a known uncoupler of oxidative phosphorylation, was not used in the early phases of the illness in any of the patients studied. Serum samples were lyophilized and reconstituted with distilled water to $20 \%$ the original volume so as to duplicate the system used by Aprille and Asimakis (12). Serum additions are henceforth referred to as volumes of concentrated serum. Samples were stored at $-20^{\circ} \mathrm{C}$ until used. Uric acid was measured spectrophotometrically in the clinical chemistry laboratory by using the Abbott A-Gent uric acid test (Abbott Laboratories, Diagnostic Div., Irving, TX), which is accurate for uric acid concentrations between 0.6 to $12.9 \mathrm{mg} / \mathrm{dl}$ with a standard deviation of $0.2 \mathrm{mg} / \mathrm{dl}$. Free fatty acid content of serum samples was determined by the thin-layer chromatography-charring method of Kritchevsky et al. (15). ${ }^{14} \mathrm{C}$-labeled cholesterol was added to all samples during the lipid extraction as a recovery standard. The micrograms of lipid measurement was calculated by taking the recovery percentage and extraction factor into account.

Urine samples were examined for organic acids by gas-liquid chromatography as described by Tanaka et al. (16). The free fatty acids in serum were extracted as described by $\mathrm{Ng}$ et al. (17) except that chloroform was used as the organic solvent and pentadecanoic acid was included as a recovery standard. The extracts that contained free fatty acids were evaporated to dryness under nitrogen, dessicated for $1 \mathrm{~h}$, and then tightly capped. The dried samples were derivatized by using $1 \mu \mathrm{l}$ of triethylamine and $40 \mu \mathrm{l}$ of $N, \mathrm{O}$-bis(trimethylsilyl)acetamide/bis silyl acetamide (BSA) injected through the rubber cap and heated at $70^{\circ} \mathrm{C}$ for $30 \mathrm{~min} .0 .5-2 \mu \mathrm{l}$ was injected into a HewlettPackard 5840A gas-liquid chromatograph (Hewlett-Packard Co., Palo Alto, CA) with a $60-\mathrm{m} \times 1.0 \mu \mathrm{m}, 0.75-\mathrm{mm}$ inner diameter glass SPB5 capillary column (Supelco Inc., Bellefonte, PA). The injection temperature and flame ionization detector temperature were 250 and $300^{\circ} \mathrm{C}$, respectively. The oven temperature was programmed to increase from 180 to $280^{\circ} \mathrm{C}$ at $3^{\circ} \mathrm{C} / \mathrm{min}$ with an initial delay of $0.5 \mathrm{~min}$ and maintained the maximum temperature for $30 \mathrm{~min}$. Monocarboxylic and dicarboxylic fatty acids were identified by comparing their retention times to the retention times of authentic standards as well as by comparing the mass spectrum of the unknown peaks to the mass spectrum of authentic standards.

Mitochondria were isolated from homogenized rat and chinchilla liver by usng the method of Bustamante et al. (18). For respiratory studies, $2.5-5.0 \mathrm{mg}$ of mitochondrial protein was added to a $1.3-\mathrm{ml}$ reaction chamber containing isotonic buffer comprising $225 \mathrm{mM}$ sucrose, $10 \mathrm{mM} \mathrm{KPO}_{4}, 5 \mathrm{mM} \mathrm{MgCl}, 20 \mathrm{mM} \mathrm{KCl}, 20 \mathrm{mM}$ triethanolamine hydrochloride, $1 \mathrm{mM}$ EGTA, and $2 \mathrm{mg} / 3 \mathrm{ml}$ of defatted BSA, pH 7.4. Respiration was assessed polarographically by using a Clarke Electrode as described by Estabrook (19). Mitochondrial respiration was measured by using $3.0 \mathrm{mM}$ malate, pyruvate, or glutamate, and $0.15 \mathrm{mM}$ succinate and active (state 3 ) respiration was initiated with $0.15 \mathrm{mM}$ ADP. $100 \mu \mathrm{M}$ octanoic acid and oleic acid were used as substrates for respiration as described by McGarry et al. (20). The ADP/O ratio was measured polarographically as described by Estabrook (19).

Rat liver mitochondria were prepared for electron microscopy according to the method of Hackenbrock (21).

ATP was measured as described by Slater (22) by coupling ATP production in the presence of glucose and hexokinase to the formation of glucose-6-phosphate. Glucose-6-phosphate was measured enzymatically by the reduction of NADP at $340 \mu$ in the presence of glucose6-phosphate dehydrogenase, as described by Slater (22) and Bergmeyer (23). Samples were measured in duplicate.

The BSA used was essentially fatty acid-free and was further purified according to the method of Chen (24) after which no fatty acid was detectable. All chemicals were obtained from Sigma Chemical Co., St. Louis, MO, except for the fatty acid standards which were obtained from PolyScience Corp., Niles, IL, and Foxboro Analab, North Haven, CT, and the trimethylsilyl/BSA which was purchased from Pierce Chemical Co., Rockford, IL.

Data are expressed as mean \pm standard error of the mean (SEM). Separation between groups was analyzed using the Student $t$ test.

\section{Results}

Effect of Reye's syndrome serum on rat liver mitochondria. Addition of RS serum or $\mathrm{N}$ serum to preparations of rat liver mitochondria produces both a transient and a sustained increase in oxygen consumption in the presence of added substrate. The transient increase in oxygen consumption is also noted in the absence of added substrate. Both the transient and sustained increments in oxygen consumption are diminished by the addition of $1 \mathrm{mM}$ EGTA to the isotonic buffer in which the mitochondria are resuspended. EGTA selectively binds $\mathrm{Ca}^{+2}$. Therefore, $1 \mathrm{mM}$ EGTA was included in both the homogenization medium and the isotonic buffer used for respiration measurements, and all data reported are from experiments using $1 \mathrm{mM}$ EGTA. The transient increase in respiration after the addition of $20 \mu \mathrm{l}$ of concentrated RS serum to the reaction chamber containing glutamate as substrate is $3.94 \mathrm{nmol}$ of $\mathrm{O}_{2} / \mathrm{min} \cdot \mathrm{mg}$ of protein for $1.0 \mathrm{~min}$. Apart from the transient stimulation there is a sustained effect of RS serum, which is most pronounced in state 4 respiration $(1.05 \pm 0.14 \mathrm{nmol}$ of $\mathrm{O}_{2} / \mathrm{min} \cdot \mathrm{mg}$ of protein; control $0.30 \pm 0.08 \mathrm{nmol}$ of $\mathrm{O}_{2} / \mathrm{min} \cdot \mathrm{mg}$ of protein) (Fig. 1).

Uric acid oxidation. Because the stimulation of respiration after the addition of RS serum has been attributed to the metabolism of uric acid present in the serum samples (13), uric acid was measured in normal and RS samples. The uric acid content is higher in RS serum (average $5.5 \mathrm{mg} / \mathrm{dl}$, range $2.3-6.8 \mathrm{mg} / \mathrm{dl}$ ) than in $\mathrm{N}$ serum (average $2.3 \mathrm{mg} / \mathrm{dl}$, range $1.3-3.2 \mathrm{mg} / \mathrm{dl}$ ) but is within normal limits for children in all cases. The degree of transient stimulation appears to correlate directly with the amount of uric acid present in the samples. Uric acid was eliminated by incubation of serum samples at room temperature for $15-20 \mathrm{~min}$ with $2.25 \mathrm{mg}$ of uricase

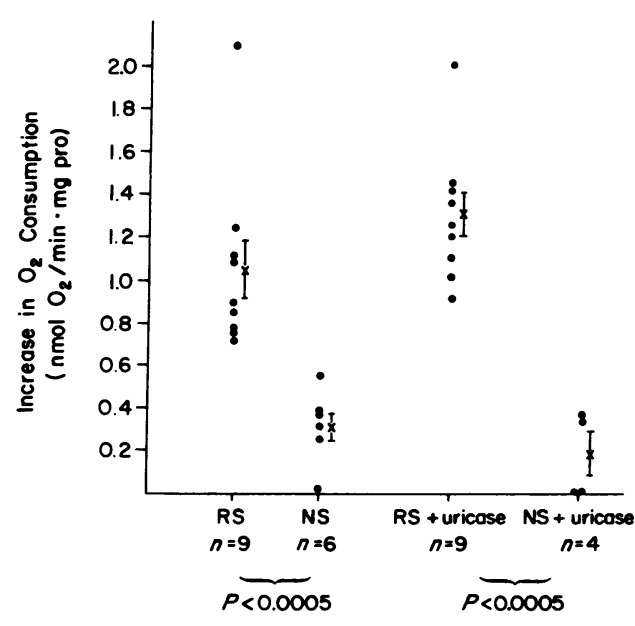

Figure 1. Change in sustained rate of state 4 oxygen consumption in isolated rat liver mitochondria. 
( $0.045 \mathrm{U}$, which is sufficient to oxidize $15 \mathrm{mg} / \mathrm{dl}$ of uric acid) before serum addition to the respiration chamber. This reduces the uric acid content to $0.1-0.9 \mathrm{mg} / \mathrm{dl}$ (average $0.5 \mathrm{mg} / \mathrm{dl}$ ), which represents the lower limit of uric acid detection by this technique. Preincubation with uricase substantially diminishes and in many cases eliminates the transient stimulation of oxygen consumption, but has no effect on the sustained increase in oxygen consumption (see Fig. 1). Addition of 10 $\mu \mathrm{l}$ of $50 \mathrm{mg} / \mathrm{dl}$ of uric acid to rat liver mitochondrial preparations produces a transient effect identical to that seen with RS serum. The contribution of uric acid to the transient stimulation of mitochondrial respiration was further assessed with the aid of oxonic acid, a potent inhibitor of uric acid oxidation (25). Oxonic acid prevents the transient stimulation of oxygen consumption induced by RS serum.

Effect of Reye's syndrome serum on respiration. To avoid the accompanying uric acid oxidation, mitochondria were prepared from chinchilla liver which lacks the uricase-containing crystalloid in its microbodies (26). Addition of $20 \mu \mathrm{l}$ of concentrated RS serum to chinchilla mitochondria using glutamate as substrate produces no transient stimulation of respiration but only a sustained increase in state 4 respiration $\left(0.65 \pm 0.06 \mathrm{nmol}\right.$ of $\mathrm{O}_{2} / \mathrm{min} \cdot \mathrm{mg}$ of protein or a $60 \%$ increase; controls $0.20 \pm 0.04 \mathrm{nmol} \mathrm{O}_{2} / \mathrm{min} \cdot \mathrm{mg}$ of protein or an $18 \%$ increase, $P<0.005$ ) (Fig. 2). This is comparable to the sustained increase in state 4 respiration measured in rat liver mitochondria after the addition of either $20 \mu$ l of uninhibited serum (1.05 nmol of $\mathrm{O}_{2} / \mathrm{min} \cdot \mathrm{mg}$ of protein) or $20 \mu \mathrm{l}$ of serum that contained sufficient oxonic acid to inhibit uric acid oxidation ( $1.53 \mathrm{nmol} \mathrm{O}_{2} / \mathrm{min} \cdot \mathrm{mg}$ of protein, a $84 \%$ increase). Additions of increasing volumes of concentrated RS serum in the range of 10-60 $\mu$ l of serum incrementally stimulates state 4 respiration in a dose-dependent linear fashion. $40 \mu \mathrm{g}$ of concentrated $\mathrm{RS}$ serum causes a mean increase in respiration

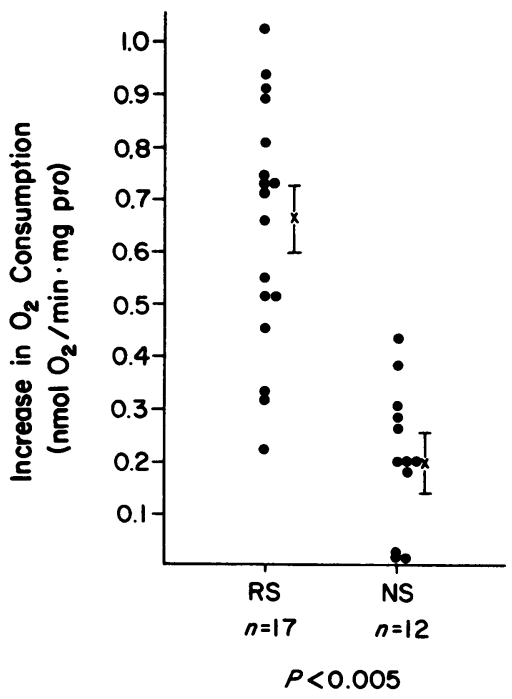

Figure 2. Change in sustained rate of state 4 oxygen consumption in isolated chinchilla liver mitochondria. $2.5-5.0 \mathrm{mg}$ of mitochondrial protein was incubated with $3 \mathrm{mM}$ glutamate and active state 3 respiration was initiated with $0.15 \mathrm{mM}$ ADP. $20 \mu \mathrm{l}$ of concentrated serum was added after the accelerated respiration of state 3 was complete. The respiratory rate was measured and compared to the state 4 respiratory rate before the addition of serum. The mean \pm standard error of the mean is given. with glutamate as substrate of $124 \pm 12 \%$, compared to a $44 \pm 8 \%$ increase by $40 \mu \mathrm{l}$ of normal serum. Fig. 3 shows that the percent stimulation of respiration plotted against the amount of serum added produces two lines, one for patients and one for controls, that are clearly distinct. Addition of 10 $\mu \mathrm{l}$ of $50 \mathrm{mg} / \mathrm{dl}$ of uric acid has no effect on the rate of oxygen consumption by the isolated chinchilla liver mitochondria.

The stimulation of respiration produced by $\mathrm{RS}$ serum could arise from the provision of a substrate for respiration that is more efficiently utilized than glutamate or an agent that affects the integrity of the mitochondrial membrane in the fashion of an uncoupler of oxidative phosphorylation. The latter effect seems to be operative in that RS serum is able to stimulate state 4 respiration in the presence of a variety of other substrates including pyruvate plus malate, succinate, oleate, octanoate, and ascorbate (Table I).

Reye's syndrome serum as source of substrate for respiration. To establish further whether the RS serum provides substrate for mitochondrial respiration or acts as an uncoupler, respiration was assessed in the absence of substrate and with selective inhibitors of respiration. With a substrate that enters the respiratory chain either at site I or site II, respiration is blocked with rotenone or antimycin, respectively, unless substrate is provided which enters the respiratory chain beyond the site of the block. Table II reveals that RS serum has a significant effect on the respiratory rate compared to control serum only in the presence of utilizable substrate. This is true when site II is isolated by using rotenone (Table II) or when site III is isolated by using antimycin (Table III); however, in these cases, RS serum does have a marked stimulatory effect on respiration in the presence of the substrate succinate and ascorbate, which enter at sites II and III of the respiratory chain, respectively (see Table I and III).

Reye's syndrome serum as a source of an uncoupler of oxidative phosphorylation. Stimulation of respiration in the presence of substrates that enter the respiratory pathway at sites I, II, or III and the absence of stimulation when effective substrate was not available suggests that the effect of RS serum on respiration is primarily an uncoupling effect. To confirm this the $\mathrm{P} / \mathrm{O}$ ratio of isolated chinchilla liver mitochondria was assessed with glutamate or pyruvate plus malate as substrate in the presence and absence of $R S$ serum. The $P / O$ ratio is an index of mitochondrial integrity. With tight coupling, the ratio is between 2-3:1 depending on the substrate, whereas with "loose" coupling a lower ratio is observed. When ADP is added in the presence of an excess of either glutamate or pyruvate plus malate as the substrate, the $P / O$ ratio was 3.33.4:1 $(n=5) .40 \mu l$ of serum from one patient with RS (patient 8, Fig. 4) reduced the $\mathrm{P} / \mathrm{O}$ ratio for mitochondria to 2.4:1 (n = 3); serum from a second patient with RS (patient 2, Fig. 4) reduced the $\mathrm{P} / \mathrm{O}$ ratio to $1.6: 1(n=2)$. The uncoupling effect of RS serum was further documented by measuring the effect of serum from a larger group of RS patients on the generation of ATP during glutamate respiration and comparing this to the uncoupler DNP (dinitrophenol). Serum from eight RS patients was used including mild and severe cases, only two of whom had detectable aspirin levels in their blood. RS serum reduced ATP formation by $15-76 \%$ compared to the effect of normal serum (Fig. 4). This confirms that a factor in RS serum uncouples oxidative phosphorylation. Candidates for this uncoupling effect were then considered.

Free fatty acids in Reye's syndrome serum. Fatty acids are 


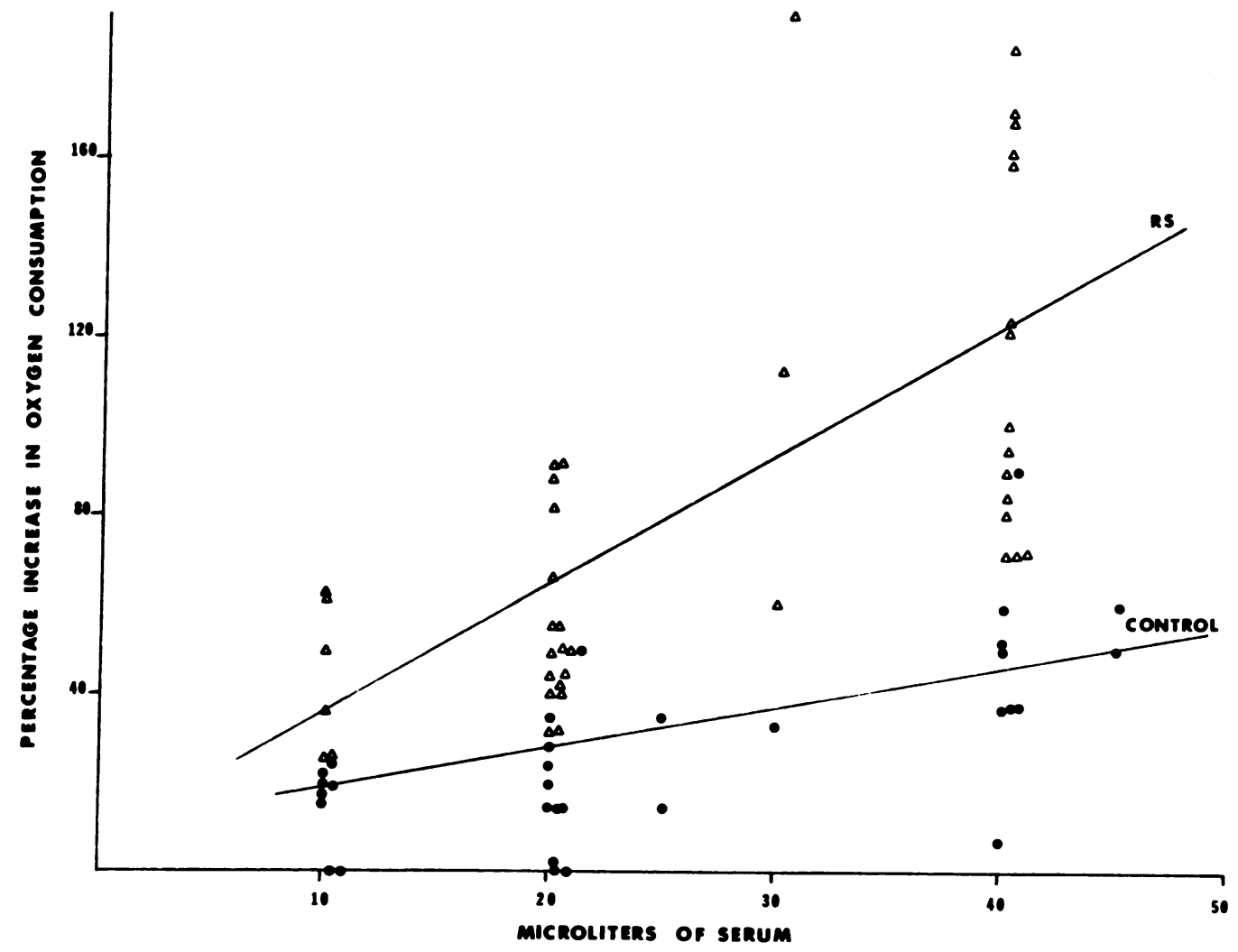

Figure 3. The stimulation of state 4 respiration by RS serum $(\Delta)$ and control serum (๑). 10-50 $\mu \mathrm{l}$ of concentrated serum was added to a reaction mixture containing chinchilla mitochondria respiring in state 4 with glutamate as substrate. The change in respiratory rate was measured as described in Fig. 2. The increase in the state 4 respiratory rate/the initial state 4 respiratory rate $\times 100$ $=$ percentage of stimulation. The percentage of stimulation was plotted against the amount of serum added and analyzed using a mode of linear regression; for the RS patients the \% stimulation $=7.7178+2.7574 \times,(r$ $=0.6845)$ and for the controls the \% stimulation $=0.7970+1.0550 \times,(r$ $=0.6074$ ). known to be elevated in RS serum and may act either as substrate or uncoupler of respiration. Normal serum has $\sim 80$ $\mu \mathrm{g} / \mathrm{ml}$ of free fatty acid while the free fatty acid concentration in serum of patients with RS varies between 80 and $900 \mu \mathrm{g} /$ $\mathrm{ml}$. Dialysis of the serum removes variable amounts of fatty acid and also diminishes the stimulation of respiration. The amount of fatty acid remaining after dialysis of the serum correlates with a residual effect on respiration. The relationship between exogenous oleate and octanoate addition to normal serum is illustrated in Fig. 5. Oleate and octanoate stimulate

Table I. Effect of RS Serum on State 4 Respiration

\begin{tabular}{lccc}
\hline & \multicolumn{3}{l}{ Percent change in state 4 respiratory rate } \\
\cline { 2 - 3 } Substrate (mM) & $\mathrm{N}$ serum & RS serum \\
\hline Glutamate (3) & $44 \pm 7.9(12)^{*}$ & $124.5 \pm 12.3(17),\{10\} \ddagger$ \\
Pyruvate/malate (3) & $38.3 \pm 1.2(3)$ & $139 \pm 31.8(7),\{4\}$ \\
Succinate (0.15) & $12.2 \pm 3.0(6)$ & $67.6 \pm 9.7(5),\{4\}$ \\
Octanoate (0.1) & $29 \pm 8.9(3)$ & $52.3 \pm 12 \quad(5),\{4\}$ \\
$\begin{array}{l}\text { Oleate (0.1) } \\
\text { Ascorbate/ } \\
\quad \text { antimycin (3) }\end{array}$ & $20 \pm 1.2(3)$ & $55.7 \pm 2.6 \quad(5),\{4\}$ \\
& $10.6 \pm 3.6(8)$ & $61.9 \pm 8.8 \quad(17),\{10\}$
\end{tabular}

Stimulation of respiration in the presence of different substrates. Respiration was assessed by using $2.5-5.0 \mathrm{mg}$ of mitochondrial protein. $40 \mu$ of normal (N) or RS serum was added as described in Fig. 2.

Percentages given in means \pm SEM.

* Number of measurements made.

$\ddagger$ Number of patients. respiration in an exponential and inverse fashion, respectively, with correlation coefficients of 0.98248 and 0.99614 . However, the amount of stimulation per microgram of measured free fatty acid in RS serum does not easily fit either the octanoic or oleic curve. The best fit statistically for the RS samples is either the linear or logarithmic function with a correlation coefficient of 0.9004 (Fig. 5).

To investigate the uncoupling potential of long- or shortchain fatty acids in RS serum, respiration was measured in the presence of antimycin (to prevent any contribution from fatty acids as substrate) with the substrate ascorbate. The effect of RS serum was compared to the stimulation by oleate or octanoate added to $\mathrm{N}$ serum. Because the uncoupling effects of free fatty acids are eliminated or attenuated by plasma

Table II. Mean Respiratory Rate

\begin{tabular}{lll}
\hline & \multicolumn{2}{l}{ Mean respiratory rate } \\
\cline { 2 - 3 } Substrate & $\mathrm{N}$ serum & RS serum \\
\hline & nmol $O_{2} /$ min $\cdot$ mg protein \\
None & $1.2 \pm 0.2(6)^{*}$ & $1.3 \pm 0.2(8),\{4\} \ddagger$ \\
Glutamate & $1.5 \pm 0.1(12)$ & $2.5 \pm 0.1(17),\{10\}$ \\
Glutamate ADP/rotenone & $0.8 \pm 0.1(6)$ & $0.6 \pm 0.2(6),\{5\}$
\end{tabular}

The effect of substrate on the stimulation of respiration by RS serum. Respiration was assessed by using $2.5-5.0 \mathrm{mg}$ of mitochondrial protein. $40 \mu$ l of normal $(\mathrm{N})$ or RS serum was added. Values given are means \pm SEM.

* Number of measurements made.

$\ddagger$ Number of patients. 
Table III. Mean Percent Change in State 4 Respiration

\begin{tabular}{|c|c|c|c|c|c|c|}
\hline \multirow{2}{*}{$\begin{array}{l}\text { Substrate/inhibitor } \\
\text { Albumin concentration }\end{array}$} & \multicolumn{2}{|l|}{ Glutamate, $3 \mathrm{mM}$} & \multicolumn{2}{|c|}{ Antimycin alone } & \multicolumn{2}{|c|}{ Antimycin/ascorbate, $3 \mathrm{mM}$} \\
\hline & $0.06 \%$ & $1 \%$ & - & $1 \%$ & $0.06 \%$ & $1 \%$ \\
\hline $\mathrm{N}$ serum & $44 \pm 8$ & $73 \pm 6$ & - & $5 \pm 3$ & $11 \pm 3$ & $20 \pm 4$ \\
\hline $\mathrm{N}$ serum + oleic, $0.4 \mathrm{mM}$ & $149 \pm 23$ & $318 \pm 156$ & - & 0 & $53 \pm 15$ & $13 \pm 8$ \\
\hline $\mathrm{N}$ serum + octanoic, $0.6 \mathrm{mM}$ & $165 \pm 16$ & - & - & $3 \pm 10$ & $17.6 \pm 12$ & $23 \pm 7$ \\
\hline Diabetic serum & $247 \pm 30$ & $187 \pm 35$ & - & $10 \pm 3$ & - & $22 \pm 3$ \\
\hline $\mathrm{N}$ serum + sebacic, $0.6 \mathrm{mM}$ & 115 & - & - & - & $40 \pm 15$ & $64 \pm 12$ \\
\hline $\mathrm{N}$ serum + adipic, $0.6 \mathrm{mM}$ & $149 \pm 13$ & $128 \pm 14$ & - & $6 \pm 5$ & $72 \pm 14$ & $111 \pm 26$ \\
\hline $\mathrm{N}$ serum $+\mathrm{C}_{18}$ dioic, $0.05 \mathrm{mM}$ & - & - & - & - & - & $74 \pm 10$ \\
\hline DNP, $0.1 \mathrm{mM}$ & $324 \pm 25$ & - & - & 0 & $92 \pm 5$ & - \\
\hline RS serum & $124 \pm 12,(10)^{*}$ & $200 \pm 10,(8)$ & - & $9 \pm 3,(7)$ & $62 \pm 9,(10)$ & $100 \pm 15,(8)$ \\
\hline
\end{tabular}

Respiration was assessed in the presence of isotonic buffer containing either $0.06 \%$ or $1 \%$ defatted albumin. $40 \mu l$ of concentrated serum was added to $2.5-5.0 \mathrm{mg}$ of mitochondrial protein. Serum was incubated with oleic, octanoic, sebacic, adipic, or octadecanedioic acid or the uncoupler DNP. The concentration of acid indicated represents the final concentration in the reaction chamber. Dash (-) indicates that the experiment was not done. Mean percent change represents the mean value of 3-11 experiments. ${ }^{*}$ Number of patients.

albumin, we also examined the influence of albumin on the stimulation of respiration induced by RS serum. Table III shows that RS serum stimulated ascorbate/antimycin respiration even in the presence of $1 \%$ defatted albumin. Medium-chain fatty acids had little stimulatory effect in the presence of either low or high albumin concentration. Although oleic acid stimulated respiration with ascorbate as substrate at low albumin concentration, the high albumin concentration sharply reduced this stimulation, an effect also noted with the serum from patients with diabetic ketoacidosis (Table III). This suggested that the stimulatory effect of RS serum was not entirely due to the presence of long-chain monocarboxylic fatty acid. Alternatively the fatty acids in RS could be unusual.

Organic acid analysis of urine from patients with RS was performed to evaluate the possibility that unusual fatty acid metabolites might accumulate in RS. Urine samples obtained at the time of presentation (i.e., before exchange transfusion) demonstrate large amounts of lactic acid $(4-6 \mathrm{mg} / \mathrm{mg}$ of creatinine) and dicarboxylic acids including adipic, suberic, and sebacic acids (total dicarboxylic acids $=1-3 \mathrm{mg} / \mathrm{mg}$ of creatinine) (27). The organic acid findings presented the possibility that the unusual effects of RS serum on respiration might be attributable in part to dicarboxylic acids. Adipic and sebacic acid as well as long-chain octadecanedioic acid added to serum stimulated respiration even in the presence of $1 \%$ albumin (Table III). $400 \mu \mathrm{M}$ sebacic or adipic acid reduces the ADP/O ratio by $25 \%$ in the presence of excess glutamate or succinate comparable to the effect of $0.05 \mathrm{mM}$ dinitrophenol. The uncoupling effects of the dicarboxylic acids, and the monocarboxylic acids oleic and octanoic, were compared by measuring their effect on ATP formation during glutamate respiration. Fig. 6 illustrates that $0.4 \mathrm{mM}$ oleate has limited effect on ATP formation whereas $0.4 \mathrm{mM}$ sebacic acid reduces ATP formation by $20 \%$ and $0.4 \mathrm{mM}$ hexadecanedioic acid reduces ATP formation to zero, comparable to the effect of DNP. The disproportionate stimulation of respiration by oleate in this experiment probably reflects its substrate properties. Dicarboxylic acids failed to stimulate respiration in submitochondrial particles capable of oxidizing succinate. As with RS serum, dicarboxylic acids also failed to stimulate oxygen consumption in the absence of substrate or in the presence of the mitochondrial poison $\mathrm{KCN}$. Thus, the stimulation of oxygen consumption by dicarboxylic acids appears to require intact, functionally active mitochondria, to depend on substrate and has the characteristics of an uncoupler such as dinitrophenol.

Dicarboxylic acids in Reye's syndrome serum. The profound reduction in ATP formation by long-chain dicarboxylic acids compared to the modest uncoupling effect of medium-chain acids raised the possibility that long-chain dicarboxylic acids might be present in RS serum. When we examined the serum of our RS patients, we found that dicarboxylic acids comprise as much as $54 \%$ of the total free fatty acids in serum. $90 \%$ of the serum dicarboxylic acids are of 16 or 18 carbon lengths in RS patients whose illness progressed to coma. No dicarboxylic acids were found in control samples, including four patients with hepatic encephalopathy, three patients with diabetic ketoacidosis, and four normal adults (Tonsgard, J. H., unpublished observation). The amount of dicarboxylic acids in the serum was compared to the effect of RS serum on ATP formation by using a group of patients that included both mild and severe cases. The extent of impairment of ATP formation in the presence of the RS serum compared to the amount of ATP formed with normal serum, corresponds directly with the amount of dicarboxylic acids in the serum. The stimulation of ascorbate respiration in the presence of antimycin, which prevents any contribution of fatty acids as substrate, also corresponds with the amount of dicarboxylic acids present in the serum. The concentration of long-chain dicarboxylic acids (16-18 carbon lengths) in RS serum is between 0.16 and 0.56 $\mathrm{mM}$ (with the final concentration in the reaction chamber $0.02-0.10 \mathrm{mM}$ ) comparable to the concentration of octadecanedioic acid used to stimulate ascorbate respiration in the presence of antimycin (Table III).

Finally, because dialysis was noted to reduce stimulation of respiration in proportion to the reduction in total free fatty acids, one dialyzed serum sample was examined for dicarboxylic acid content. The free fatty acid content was reduced $80 \%$ by 


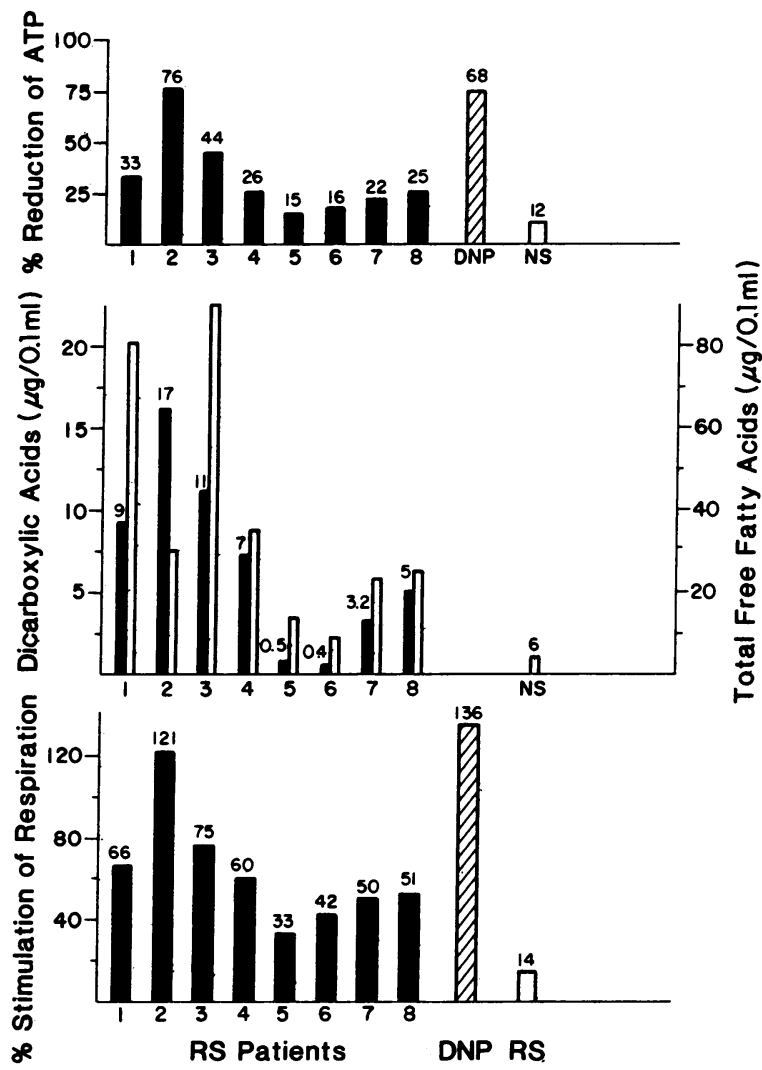

Figure 4. The effect of RS serum on ATP formation. Respiration was assessed with $5 \mathrm{mg}$ of mitochondrial protein in isotonic buffer containing $0.5 \mathrm{M}$ glucose and $3 \mathrm{mM}$ glutamate and $66 \mathrm{mg} / \mathrm{dl}$ of defatted albumin. After $5.0 \mathrm{~min}, 10 \mathrm{U}$ of hexokinase was added followed by $40 \mu \mathrm{l}$ of normal serum or RS serum or $0.1 \mathrm{mM}$ DNP. After $2.0 \mathrm{~min}$ $420 \mathrm{nmol}$ of ADP was added. The reaction was terminated with $35 \%$ perchloric acid. The reaction mixture was reserved for ATP determination. Determinations were made in duplicate. The RS patients included two patients with mild disease that did not progress to coma (patients 5 and 6) and two patients with detectable aspirin levels (patients 4 and 7). The percent reduction of ATP formation $=100$ - (nanomoles of ATP formed in the presence of RS serum or DNP/ nanomoles of ATP formed in the presence of normal serum). The effect of normal serum (NS) on ATP formation is included for the purpose of comparison. The effect on ATP formation is compared to the amount of dicarboxylic acids present in the serum samples (shaded bars) and the total free fatty acids in serum (open bars) and to the percent stimulation of state 4 respiration in the presence of 1 $\mu \mathrm{g}$ of antimycin and $3 \mathrm{mM}$ ascorbate.

dialysis. The dicarboxylic acid content prior to dialysis was $12.0 \%$ of total free fatty acids and $14.6 \%$ of the total free fatty acids after dialysis, indicating that dicarboxylic and monocarboxylic acids are similarly reduced by dialysis.

Reye's syndrome serum and mitochondrial ultrastructure. Because uncouplers may affect mitochondrial ultrastructure, the effect of RS serum on the appearance of isolated liver mitochondria was explored. Hackenbrock (21) has shown that isolated liver mitochondria are usually in a condensed form and that with active respiration the majority of mitochondria expand. Uncoupling agents accelerate this expansion and may result in swelling and disruption of mitochondria. Addition of $40 \mu \mathrm{l}$ of RS serum increased the number of expanded mitochondria compared to the addition of similar amounts of
\% fatty acid stimulation
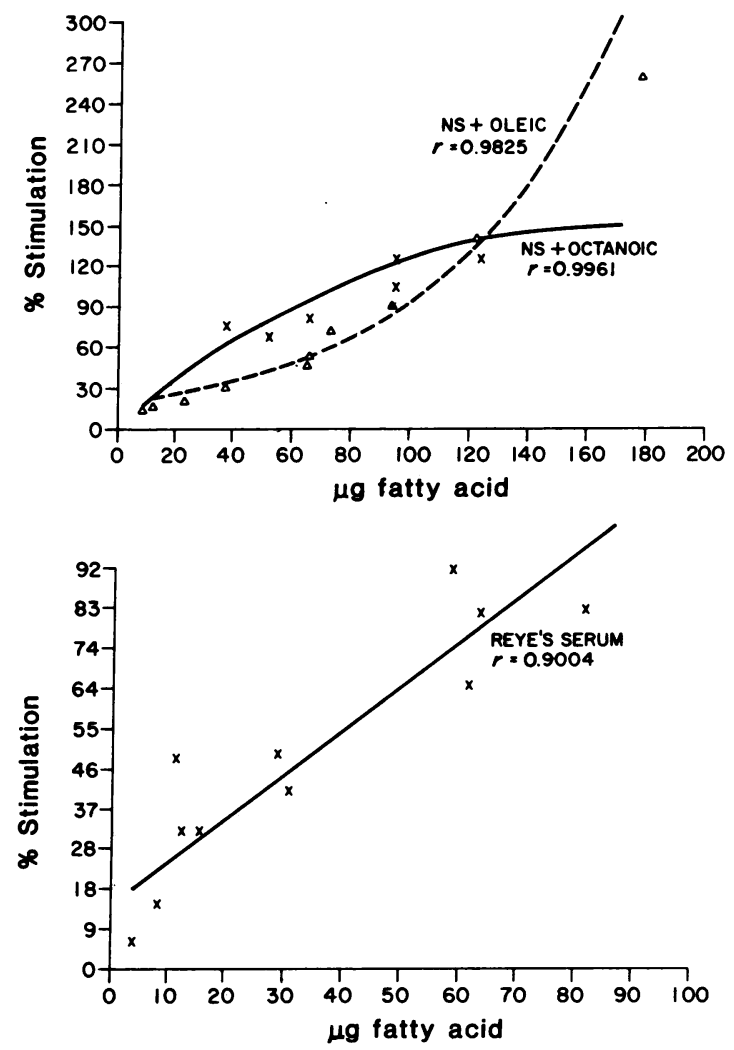

Figure 5. Comparison of the stimulation of respiration by RS serum to that by monocarboxylic fatty acids added to normal serum (NS). The percent change in respiratory rate was measured as described in Figs. 2 and 3.

normal serum. Mitochondria incubated with RS serum also appeared less dense and in some cases swollen or disrupted (Fig. 7).

\section{Discussion}

We have shown that there is an endogenously produced substance in RS serum which perturbs the function of isolated hepatic mitochondria. This perturbation takes the form of a stimulation of state 4 respiration and uncoupling of oxidative phosphorylation, with an associated expansion and some distortion of mitochondria. The stimulation of oxygen consumption by RS serum had been attributed to the oxidation of uric acid by uricase containing microbodies contaminating rat liver mitochondrial preparations (13). Though we have reproduced this effect, it does not account for most of the respiratory stimulation observed. Uric acid is present in slightly elevated concentrations in patients with RS and the oxidation of uric acid in these samples does produce a transient increase in oxygen consumption, but $\mathrm{RS}$ serum also induces a sustained incremental response which is not diminished by preincubation of the serum with uricase, by inhibition of uric acid oxidation with oxonic acid, or by using isolated chinchilla liver mitochondria that lack uricase-containing microbodies.

The effect of RS serum on isolated hepatic mitochondria is best evaluated by using chinchillas where the effect of uric acid and uricase does not complicate the interpretation. The 

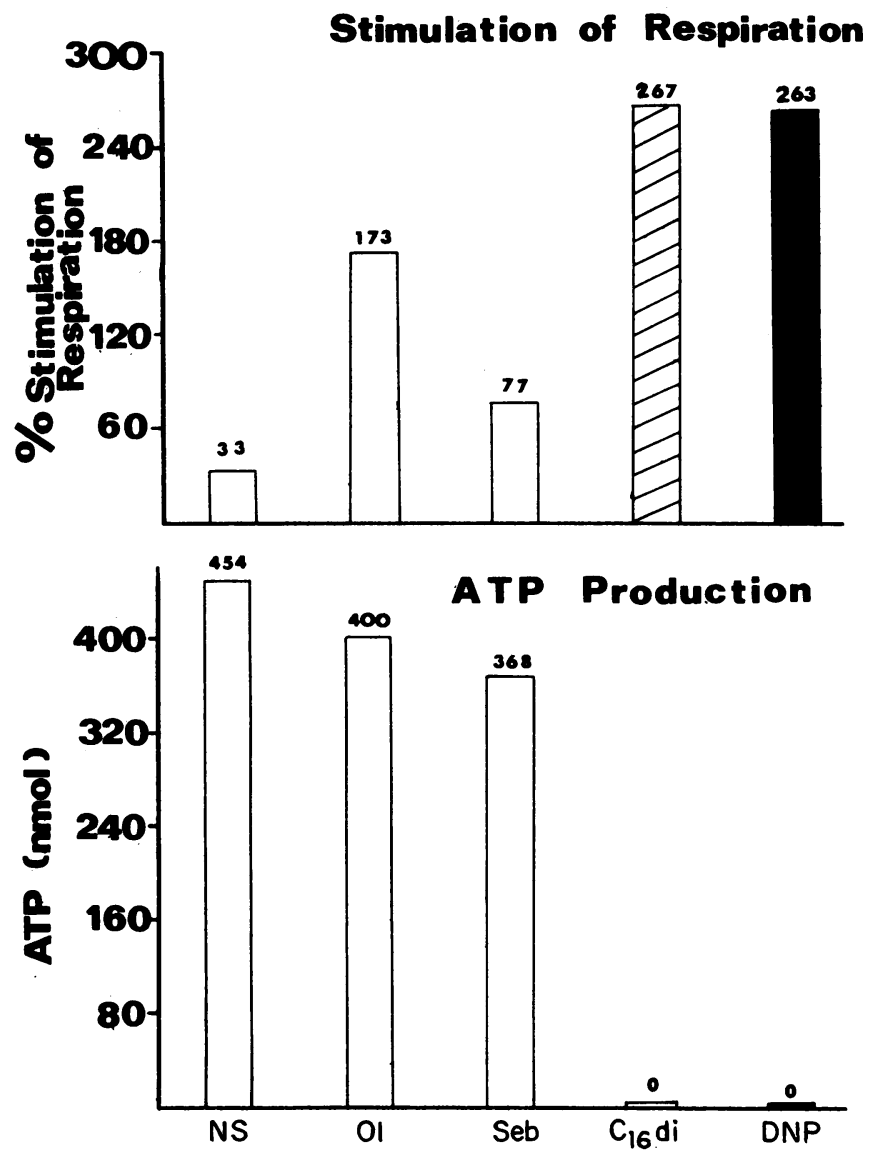

Figure 6. The effect of monocarboxylic and dicarboxylic fatty acids on ATP formation. Respiration was assessed with $3 \mathrm{mg}$ of mitochondrial protein in isotonic buffer containing $0.5 \mathrm{M}$ glucose and $3 \mathrm{mM}$ glutamate and $1 \%$ defatted albumin. $40 \mu \mathrm{l}$ of serum was added. Serum was preincubated with $0.4 \mathrm{mM}$ oleic, sebacic, or hexadecanedioic acid or $0.1 \mathrm{mM}$ DNP (final concentration in the reaction chamber) as indicated. Nanomoles of ATP formed was determined as described in Fig. 4. State 2 respiratory rate was determined before and after the addition of serum.

stimulation of respiration in this preparation is apparent only in the presence of substrate. RS serum stimulates oxygen consumption when added to mitochondria in the absence of exogenous ADP (state 4 respiration) with excess glutamate, succinate, oleate, octanoate, ascorbate, or pyruvate plus malate as substrate. This is most easily explained by the presence in RS serum of an uncoupler of oxidative phosphorylation.

That RS serum stimulates respiration notably in the presence of the inhibitors rotenone and antimycin only upon addition of exogenous substrate that enters the respiratory pathway beyond the site of the block argues strongly for an uncoupling effect. No respiratory stimulation is observed in the presence of rotenone or antimycin but of no alternative substrate, indicating that RS serum does not itself contain a site II or III substrate. Provision of such a substrate permits the expression of the uncoupling effect. Although the stimulation of respiration induced by RS serum or dicarboxylic acids is demonstrable only when the availability of ADP is limiting (state 4), the uncoupling effect is nevertheless also evident when ADP is available (state 3 ) as revealed by the reduction of $\mathrm{P} / \mathrm{O}$ ratios or the decreased production of ATP by $15-76 \%$.

The stimulation of state 4 respiration appears to correlate with the level of free fatty acids in the serum samples. Dialysis of serum samples diminishes the free fatty acid content to a variable extent; the subsequent ability of these samples to stimulate respiration correlates with the amount of free fatty acids remaining. The concentration of free fatty acids present in patients with RS is between 80 and $900 \mu \mathrm{g} / \mathrm{ml}$. However, addition of monocarboxylic fatty acid or diabetic serum to mitochondria respiring in the presence of antimycin and ascorbate and $1 \%$ defatted albumin produces little respiratory stimulation, whereas RS serum does have a stimulatory effect under those conditions. Moreover, addition of incremental amounts of oleate or octanoate to $\mathrm{N}$ serum relates to respiratory stimulation by an exponential or inverse function respectively with a tight correlation coefficient, whereas the degree of stimulation by RS serum correlates with the fatty acid content by a linear function. This argues strongly that the stimulatory effect of RS serum is at least partly due to a substance other than fatty acid or that the fatty acid is unusual in that its binding to albumin is altered.

The presence of dicarboxylic acids in RS urine samples suggested that the effects of dicarboxylic acids should be explored. The dicarboxylic acids tested appear to have the properties of uncouplers that are required of the component's activity in RS serum and, like the latter, also stimulate respiration in the presence of antimycin and ascorbate even with $1 \%$ albumin. This argues that the uncoupling effect of RS serum may be attributable to the presence of dicarboxylic acids or a compound with very similar functional properties in the serum of these patients. The uncoupling effect of dicarboxylic acids is clearly demonstrated by the marked reduction of ATP formation that they induce. When free fatty acids were examined in the RS serum samples, dicarboxylic acids were found in all of the patients and comprised as much as $54 \%$ of the total free fatty acids in the serum. In two mild cases of RS the majority of the dicarboxylic acids were of medium chain length whereas, in severe cases of RS, $90 \%$ of the dicarboxylic acids were of 16 or 18 carbon lengths which are potent uncouplers in vitro. Dialysis reduces the total free fatty acids but does not appreciably alter the proportion or type of dicarboxylic acids present. Comparison of dicarboxylic acid content to the effect of RS serum on ATP formation and respiration shows that the amount of dicarboxylic acids present in the serum corresponds directly with the impairment of ATP formation and stimulation of state 4 ascorbate respiration. The concentration of long-chain dicarboxylic acids in the serum of the RS patients was $0.16-0.56 \mathrm{mM}$ (the final concen-
Figure 7. Effect of RS serum on mitochondrial ultrastructure. $3 \mathrm{mg}$ of mitochondrial protein was incubated in well-oxygenated isotonic buffer in a 1.3-ml chamber with a Clarke electrode. Active respiration was initiated with $3 \mathrm{mM}$ glutamate and $0.15 \mathrm{mM}$ ADP. After the ADP was consumed, $40 \mu$ l of concentrated normal serum (shown below) or RS serum (above) was added and allowed to incubate with the mitochondrial preparation for $20 \mathrm{~min}$. After $20 \mathrm{~min}, 100 \mu \mathrm{l}$ was removed for fixation and sectioning. The fixative used was $2 \%$ osmium tetroxide in a sodium phosphate buffer adjusted to equal the osmolarity and $\mathrm{pH}$ of the reaction media. Electron micrographs: $\times 27,000$. 

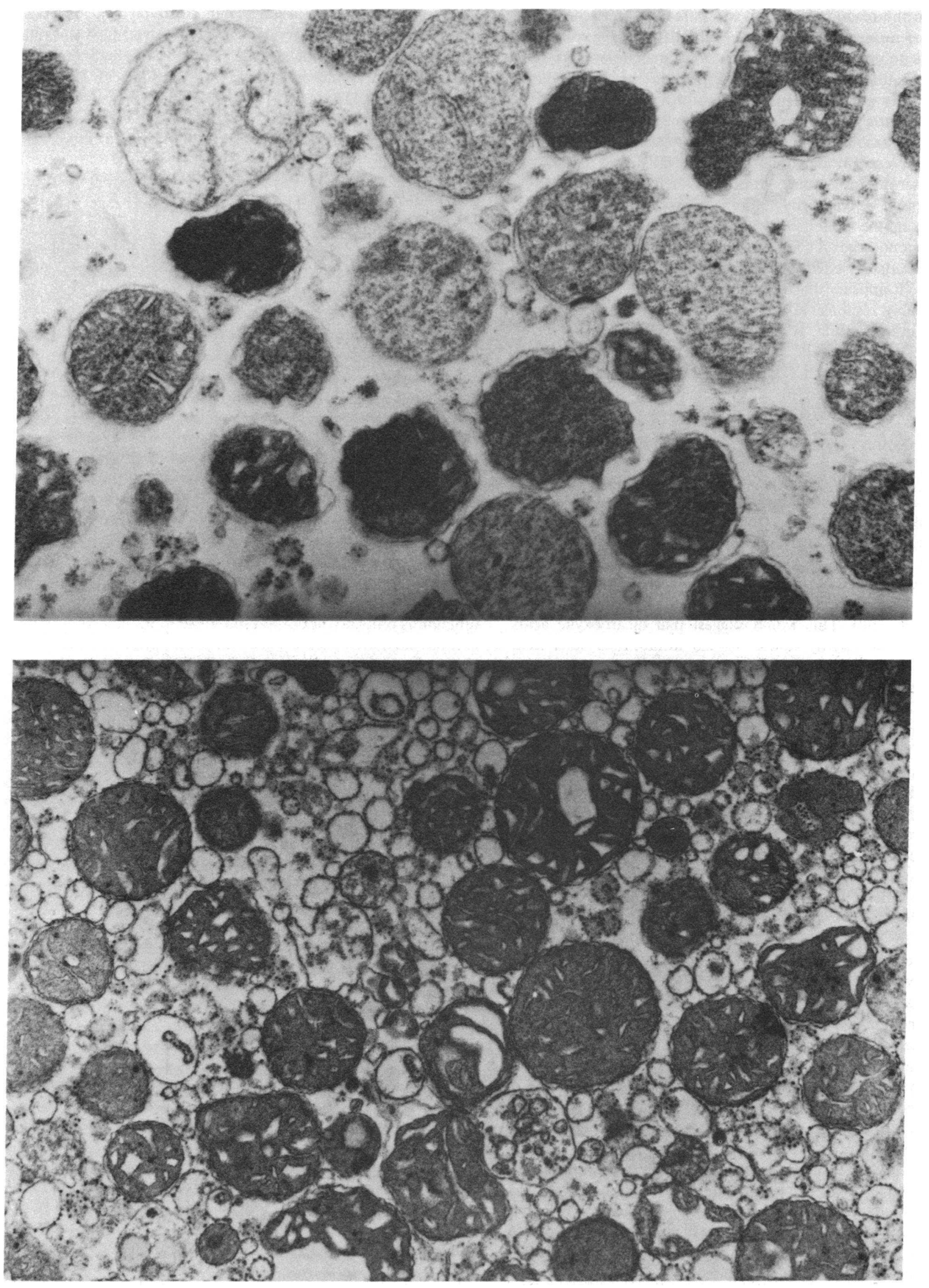
tration in the reaction chamber was $0.02-0.10 \mathrm{mM}$ ) which is within the range $(0.05-0.40 \mathrm{mM}$, Table III and Fig. 6) demonstrated to stimulate respiration and uncouple oxidative phosphorylation. Dicarboxylic acids therefore seem to account for the observed uncoupling effect of RS serum in that $N$ serum has little effect on ATP formation. Dicarboxylic acids also seem to account for much of the stimulation of respiration; however, $\mathrm{N}$ serum or monocarboxylic fatty acid added to normal serum have some stimulatory effect on respiration which cannot be completely eliminated even with ascorbate as substrate in the presence of antimycin. This would suggest that the monocarboxylic fatty acids in RS serum may contribute to the stimulatory effect on respiration.

Thus, it appears that free dicarboxylic acids in RS serum are probably responsible for much of the effect observed on isolated mitochondria. A significant uncoupling effect of medium-chain dicarboxylic acids has recently been noted by other investigators (28). The continued expression of dicarboxylic acid toxicity even in the presence of a relatively large concentration of albumin is not surprising. The hydrophilic group at each end of the molecule would result in a U-shaped orientation at a lipid-water boundary and in a too-restricted hydrophobic domain to bind effectively to the high-affinity fatty acid binding site of albumin (29) and, perhaps, also the liver fatty acid binding protein. Intracellularly, fatty acid binding protein appears to play an important role in fatty acid binding and transport analogous to the extracellular role of albumin. Models of the secondary structure of fatty acid binding protein suggest that fatty acids bind in a similar way to albumin (30). This would suggest that dicarboxylic acids would not be readily bound to the intracellular fatty acid binding protein. However, further studies will be required to demonstrate this.

It is of interest that such a molecule should be capable of disrupting the functional integrity of the mitochondrial membrane. The mechanism of this disruption remains to be clarified. The origin of dicarboxylic acids is not clear except that they are products of $\omega$-oxidation in microsomes and appear during starvation to a slight degree and to a much larger extent in disorders in which $\beta$-oxidation is impaired (31).

Defects of $\beta$-oxidation are clinically similar to RS and there are several reports of patients with recurrent episodes of RS who were subsequently shown to have defects in fatty acid metabolism (32-36). Hydroxymethyl glutaryl CoA lyase deficiency $(35,36)$, ethylmalonic adipicaciduria (37), and systemic carnitine deficiency $(32,33)$, and some cases of medium-chain acyldehydrogenase deficiency $(38,39)$ and glutaric aciduria (40) present with altered mental status, abnormal liver function tests, and marked to moderate elevations in blood ammonia associated with medium-chain dicarboxylic aciduria. Jamaican vomiting sickness is characterized by dicarboxylic aciduria and abnormal liver function tests as well and has markedly elevated serum glutamine and glutamic acid, suggesting that hyperammonemia is also part of this illness (41). However, although a general impairment of liver function is present in the majority of patients with dicarboxylic acid formation, hyperammonemia is not associated with all patients in which dicarboxylic aciduria has been noted. This may be due to the amount or, more importantly, the chain length of the dicarboxylic acids formed. The spectrum of diseases associated with dicarboxylic acids in the urine needs to be reinvestigated with special emphasis on the nature of the dicarboxylic acids present in the serum. RS is the first disease in which long-chain dicarboxylic acids have been demonstrated. $\mathrm{Ng}$ et al. (17) demonstrated significant amounts of long-chain dicarboxylic acids in one patient with RS, and we have found long-chain dicarboxylic acids in 14 of our RS patients (Tonsgard, J. H., unpublished observation). Long-chain dicarboxylic acids, even in low concentration, are much more potent uncouplers than medium-chain dicarboxylic acids.

The stimulation of respiration and ultrastructural changes in isolated mitochondria suggests that a disturbance in fatty acid metabolism leading to the accumulation of dicarboxylic acids is closely associated with the illness and may potentiate the mitochondrial dysfunction in RS. This is supported not only by the presence in the serum and urine of dicarboxylic acids which are products of w-oxidation, but by the massive free fatty acidemia and fatty deposition of the viscera and by the correlation of plasma lactate and blood ammonia to the urinary excretion of ketones and dicarboxylic acids or to the concentration of serum dicarboxylic acids (Tonsgard, J. H., unpublished observation).

Because of their highly charged nature and their effect on mitochondria in the presence of defatted albumin, we suspect that dicarboxylic acids are not readily bound in the serum or the cytosol. It is our hypothesis that dicarboxylic acids formed in RS and other metabolic disorders are unbound in hepatocytes and able to act as uncouplers of oxidative phosphorylation, reducing mitochondrial energy production and those mitochondrial processes dependent on it. This hypothesis is the subject of continuing investigation. Such mitochondrial dysfunction is probably important in the pathophysiology of those illnesses associated with a notable impairment of mitochondrial fatty acid oxidation. The ability to inhibit the production of dicarboxylic acids in the liver, or to neutralize them once formed, may be a useful adjunct to the treatment of RS and related disorders. Measurement of serum dicarboxylic acids may be an important parameter to assess in RS and other diseases. A much more detailed study of the formation and biologic properties of dicarboxylic acids therefore seems justified.

\section{Acknowledgments}

The authors would like to express their gratitude to R. Thisted, Ph.D., Statistics Department, University of Chicago, for his assistance, to Peter R. Huttenlocher, University of Chicago, for the serum samples, to Zdenek Hruban, M.D., for his advice regarding uric acid metabolism, and to A. Marbella and L. Van Melle for their outstanding technical assistance. Mass spectroscopy was performed with the assistance of Josef Fried, Ph.D., Department of Chemistry, University of Chicago. This work was supported in part by the Children's Research Fund and the Louis Block Fund, University of Chicago, and grants HD-04583 and NS-17601 from the U. S. Public Health Service.

\section{References}

1. Huttenlocher, P. R., and D. Trauner. 1977. Reye's syndrome. In Handbook of Clinical Neurology. P. J. Vinken and G. W. Bruyn, editors. North Holland, Amsterdam. 335-344.

2. Chaves-Carballo, E., G. A. Carter, and D. A. Wiebe. 1979. Triglyceride and cholesterol concentrations in whole serum and in lipoproteins in Reye syndrome. Pediatrics. 64:592-597.

3. Haymond, M. W., I. E. Karl, J. P. Keating, and D. C. DeVivo. 1978. Metabolic response to hypertonic glucose administration in Reye syndrome. Ann. Neurol. 3:207-215.

4. Bove, K. E. 1975. The character and specificity of the hepatic 
lesion in Reye's syndrome. In Reye's Syndrome. J. D. Pollack, editor. Grune \& Stratton, New York. 93-116.

5. DeVivo, D. C. 1978. Reye syndrome: A metabolic response to an acute mitochondrial insult. Neurology. 28:165-168.

6. Partin, J. C. 1975. Liver ultrastructure in Reye's syndrome. In Reye's Syndrome. J. D. Pollack, editor. Grune \& Stratton, New York. 117-129.

7. Sinatra, F., T. Yoshida, M. Applebaum, W. Mason, N. J. Hoogenraad, and P. Shinshine. 1975. Abnormalities of liver carbamyl phosphate synthetase and ornithine transcarbamylase in liver of patients with Reye's syndrome. Pediatr. Res. 12:1045-1047.

8. Tonsgard, J. H., and P. R. Huttenlocher. 1982. Reye's Syndrome. In Recent Advances in Clinical Neurology. W. B. Matthews and G. H. Glaser, editors. Churchill-Livingstone, Edinburgh. 169-182.

9. Marder, H. K., C. F. Strife, J. Forristal, J. S. Partin, and J. C. Partin. 1980. Reye's syndrome: hypocomplementemia related to clinical staging. Pediatr. Res. 14:505a. (Abstr.)

10. Medof, M. E., J. P. Antel, A. Li, R. P. Roos, and P. R. Huttenlocher. 1980. Persistent Raji cell reactivity in sera from patients with Reye's syndrome. Clin. Res. 28:374a. (Abstr.)

11. Aprille, J. R. 1977. Reye's syndrome: patient serum alters mitochondrial function and morphology in vivo. Science (Wash. DC). 197:908-910.

12. Aprille, J. R., and G. K. Asimakis. 1977. Reye's syndrome: the effect of patient serum on mitochondrial respiration in vitro. Biochem. Biophys. Res. Commun. 79:1122-1129.

13. Aprille, J. R., J. Austin, C. E. Costello, and N. Royal. 1980. Identification of the Reye's syndrome "serum factor." Pediatr. Res. 14:1215a. (Abstr.)

14. Keller, W. J. 1947. A rapid method for the determination of salicylates in serum or plasma. Am. J. Clin. Pathol. 17:415-417.

15. Kritchevsky, D., L. M. Davidson, H. K. Kim, and S. Malhotra. 1973. Quantitation of serum lipids by a simple TLC-charring method. Clin. Chim. Acta. 46:63-68.

16. Tanaka, K., D. G. Hine, A. West-Dull, and T. B. Lynn. 1980. Gas-chromatography method for analysis of urinary organic acids. Clin. Chem. 26:1839-1853.

17. Ng, K. J., B. D. Andresen, M. D. Hilby, and J. R. Bianchine. 1983. Identification of long chain dicarboxylic acids in the serum of two patients with Reye's syndrome. J. Chromatogr. 276:1-10.

18. Bustamante, E., J. W. Saper, and P. L. Pedersen. 1977. A high yield preparative method for isolation of rat liver mitochondria. Anal. Biochem. 80:401-409.

19. Estabrook, R. W. 1967. Mitochondrial respiratory control and the polarographic measurement of ADP:O ratios. Methods Enzymol. 10:41-47.

20. McGarry, J. D., G. P. Mannaerts, and D. W. Foster. 1977. A possible role for malonyl $\mathrm{CoA}$ in the regulation of hepatic fatty acid oxidation and ketogenesis. J. Clin. Invest. 60:265-270.

21. Hackenbrock, C. R. 1966. Ultrastructural bases for metabolically linked mechanical activity in mitochondria. J. Cell Biol. 30:269-297.

22. Slater, E. C. 1967. Application of inhibitors and uncouplers for a study of oxidative phosphorylation. Methods Enzymol. 10:4856.

23. Hohorst, H.-J. 1963. D-Glucose-6-phosphate and D-fructose6-phosphate. In Methods of Enzymatic Analysis. H.-U. Bergmeyer, editor. Academic Press, New York. 134-138.
24. Chen, R. F. 1967. Removal of fatty acids from serum albumin by charcoal treatment. J. Biol. Chem. 217:173-181.

25. Fridovich, I. 1965. The competitive inhibition of uricase by oxonate and by related derivatives of s-triazines. J. Biol. Chem. 240: 2491-2494.

26. Hruban, Z., and M. Recheigel. 1969. Microbodies and Related Particles. Academic Press, Inc., New York. 36.

27. Tonsgard, J. H. Urinary dicarboxylic acids in Reye's syndrome. J. Pediatr. In press.

28. Passi, S., M. Picardo, M. Nazzaro-Poro, A. Breathnach, and A. M. Contaloni. 1983. Effect of medium chain length dicarboxylic acids on mitochondrial respiration. J. Invest. Dermatol. 80:350a. (Abstr.)

29. Spector, A. A., K. John, and J. E. Fletcher. 1969. Binding of long-chain fatty acids to bovine serum albumin. J. Lipid Res. 10:5667.

30. Gordon, J. I., D. H. Alpers, R. K. Ockner, and A. W. Strauss. 1983. The nucleotide sequence of rat liver fatty acid binding protein mRNA. J. Biol. Chem. 258:3356-3363.

31. Mortenson, P. B. 1981. $C_{6}-C_{10}$ dicarboxylic aciduria in starved, fat-fed and diabetic rats receiving decanoic acid or medium-chain triacylglycerol. Biochim. Biophys. Acta. 664:349-355.

32. Karpati, G., S. Carpenter, A. G. Engel, G. Watters, J. Allen, S. Rothman, G. Klassen, and O. A. Mamer. 1975. The syndrome of systemic carnitine deficiency. Neurology. 25:16-24.

33. Glasgow, A. M., G. Eng, and A. G. Engel. 1980. Systemic carnitine deficiency simulating recurrent Reye syndrome. J. Pediatr. 96:889-891.

34. Robinson, B. H., J. Oei, W. G. Sherwood, A. H. Slyper, J. Heininger, and O. A. Mamer. 1980. Hydroxymethylglutaryl CoA lyase deficiency: features resembling Reye Syndrome. Neurology. 30:714 718.

35. Leonard, J. V., J. W. T. Seakins, and N. K. Griffin. 1979. $\beta$ Hydroxy- $\beta$-methylglutaricaciduria presenting as Reye's syndrome. Lancet. 1:680-681.

36. Gregersen, N., H. Wintzensen, K. E. Christensen, M. F. Christensen, N. J. Brandt, and K. Rasmussen. 1982. $C_{6}-C_{10}$ dicarboxylic aciduria. Pediatr. Res. 16:861-868.

37. Mantagos, S., M. Genel, and K. Tanaka. 1979. Ethylmalonicadipic aciduria. J. Clin. Invest. 64:1580-1589.

38. Stanley, C. A., D. E. Hale, P. M. Coates, C. L. Hall, H. Corkey, W. Yang, R. I. Kelley, E. L. Gonzales, J. R. Williamson, and L. Baker. 1983. Medium-chain acyl-CoA dehydrogenase deficiency in children with non-ketotic hypoglycemia and low carnitine levels. Pediatr. Res. 17:877-884.

39. Gregersen, N., S. Klvraa, P. D. Mortensen, and K. Rasmussen. 1982. $C_{6}-C_{10}$ dicarboxylic aciduria: Biochemical considerations in relation to diagnosis of beta-oxidation defects. Scand. J. Clin. Invest. 161:15-27.

40. Goodman, S. I., D. O. Steve, E. R. McCabe, M. D. Norenberg, R. H. Shikes, D. A. Stumpf, and G. K. Blackburn. 1982. Glutaric aciduria type II: Clinical, biochemical, and morphologic considerations. J. Pediatr. 100:946-950.

41. Shih, V. E., and K. Tanaka. 1978. Plasma and urine amino acid changes in rats treated with hypoglycin. Clin. Chim. Acta. 88: 539-543. 